\title{
Brexit in Air Transport after 2020
}

\author{
Andrea Brezonakova ${ }^{1, *}$, Benedikt Badanik ${ }^{1}$, and Robin Davies ${ }^{2}$ \\ ${ }^{1}$ University of Zilina, Faculty of Operation and Economics of Transport and Communications, \\ Department of Air Transport, Univerzitna 1, 01026 Zilina, Slovakia \\ ${ }^{2}$ Flight Safety Volunteer, United Kingdom
}

\begin{abstract}
.
Research background: The authors are providing an update to the ongoing process of Brexit and the negotiations between the UK and the EU, following their own previous research in this area.

Purpose of the article: In 2019, the aviation sector in the UK ranked as the third largest in the world. London Heathrow, a hub to many UK airlines, ranked as Europe's busiest airport and seventh busiest in the world. [1] Brexit negotiations between the UK and the EU, in the context of globalization and the existing deep ties within the EU institutions, presents a complex task. Following the Brexit referendum in June 2016, where the majority of the electorate decided that Britain should leave the EU, events have progressed significantly by the UK leaving the EU formally at 23:59 on the 31 st January 2020. However, negotiations are still ongoing and when it comes to Aviation, the outcome in many key areas is still uncertain.

Methods: The article is based on data and information collation as well as the authors' experience within the industry.

Findings \& Value added: Once the transition period terminates on the 31 st December 2020, Brexit will have a significant influence on trading in the European domestic market and globally on the international market. This paper discusses available options for the UK and the EU that follow from existing decisions in the Brexit bill, as well as outlining possible future developments. Furthermore, in light of the existing threats to the Aviation industry from the ongoing COVID-19 pandemic and the cessation of air travel for many weeks, adjustments to the Brexit plan might be required.
\end{abstract}

Keywords: globalization; Brexit; aviation; airline industry; EU-UK relationships

JEL Classification: F53; F68; L93

\footnotetext{
* Corresponding author: ada.brezonak@gmail.com
} 


\section{Introduction}

The industry has changed significantly in the past 25 years. Important changes have been driven by globalization, market liberalization and integration of European states into the Joint Aviation Authorities (JAA) and subsequently EASA. The European Single Market removed trade barriers and allowed free movement of goods, people, services and capital, whilst common policies and regulations were maintained. Furthermore, Single European Skies laid down regulations on framework, service provision, airspace and interoperability. Both of these projects are considered to be major achievements of the European Union and its predecessor, the European Community. A high level of integration and liberalization enabled the EU member states to enjoy free market privileges which in the aviation industry led to the establishment of several low-cost airlines, increased competition and industry growth overall.

Industries in the United Kingdom would benefit from access to other EU markets and an enhanced level of cooperation, helping the UK to become the world's third largest aviation industry and second largest aircraft manufacturer [2]. The Open Skies agreement enabled London Heathrow, one of the world's busiest airports, to become an important hub for transatlantic travel with an estimate of $40 \%$ of all flights from Europe departing to the US [3], from this airport. The UK also represents the EU's largest aviation market with a high level of interdependence with the EU [4]. EU membership helped the UK to improve macroeconomics, trade and competition, not only in the aviation industry [5]. Therefore, the consequences of Brexit are wide and far-reaching, affecting many government policies that shape the environment in which British companies operate [6].

This also applies to airports. Improving an airport's position in the network of air links has a positive effect on local economic activity. Air links increase business links, showing that the movement of people fosters the movement of capital. In particular, this is driven mostly by capital flowing from high-income to middle-income (but not low-income) countries. Taken together, this suggests that increasing interconnectedness induces links between businesses and generates economic activity at the local level but also gives rise to increased spatial inequality locally, and potentially globally [7].

Civil aviation is one of the most heavily regulated industrial sectors with rules enacted on multilateral, regional and domestic stages where law is instituted at the supranational level [4]. Wide harmonization of rules in Europe was achieved with EASA, the European Aviation Safety Agency. The UK Civil Aviation Authority (UK CAA) provided their expertise at the establishment stage of EASA, and it is estimated that this participation created $80-90 \%$ of the overall EASA expertise. Brexit brings in the requirement for a re-evaluation of numerous policies in regulatory regimes and their mutual recognition, civil aviation included [8], in order to avoid a disruptive outcome.

Aviation is also an international business by its very nature. One that prospers at most in a liberal environment; and certainly, it does not benefit from any level of imposed restrictions, may it be border closures or a governments protectionism. It has been recognized that liberalization promotes fair competition [9] but also decreases prices and increases passenger volumes $[10,11]$. Therefore, it is expected that services vulnerable or exposed to Brexit may launch subsidiaries in other EU countries to bypass new protectionism [12]. Brexit by itself could be described as a protectionist intention that looks at its own market prosperity rather than the consequences of introducing trade barriers in a globalized world. Brexit might also be a populistic response after a delocalization; or slowbalization respectively. Namely, the global volume of merchandise traded slowed down dramatically and even went in reverse in 2019 in contrast to a 21 st century average growth rate of about $3.4 \%$ per annum [13]. Had there been no pandemic in 2020, the global HDP growth had been estimated to slow down. The US economic activity was expected to expand by around $2 \%$, whilst an expected rate for 
the Eurozone was of $1 \%$ only, with a projection of a real GDP growth for the UK of $1.2 \%$ in 2020 .

\section{Methodology}

This article is a revision of previously published articles on the topic of Brexit with respect to Aviation $[14,15]$. The authors recognize that this area is dynamic and the outcome remains uncertain. There are several existing ties between the EU and UK in a form of various agreements and cooperation projects, such as Single European Skies, and GALILEO; but also free movement across borders and the privileges of ICAO freedoms of the air. Thus, any form of negotiation concerning the aviation industry is expected to be a complex dialogue.

The methodology used here has been via paper review, observation, deduction, and field experience. The first method mentioned - a paper review - appeared to be the most challenging due to the lack of scientific literature available. Therefore, the authors had to rely mostly (apart from own field experience), on relevant business and media reports. It has also been observed that most of the relevant cited information has been repeatedly appearing in other study material.

\section{Results}

\subsection{Current state of the Industry}

Aviation activity in the EU and in the UK is ruled by thousands of legal acts. These acts that are instituted at the national, EU and international multilateral levels, set up various regulatory systems [16].

The UK's withdrawal from the European Union following the results of the referendum leaves a lot of uncertainty for the future in many areas and particularly air transport due to its high degree of regulation and international nature [17]. Up until now, the results of the Brexit referendum have had a few direct effects on the tourism market, but led to a substantial fall in the value of the British pound and reduced share price of tourism and hospitality companies [18].

Following the Brexit referendum vote and the actual withdrawal from the EU on the 31 st January 2020, the United Kingdom entered the transition period which guarantees the same conditions and privileges as any EU member state but, excludes voting rights. Since the referendum vote, discussions were held about potential Brexit scenarios and the extent to which ties bind the UK and the EU. Third country agreements, especially those with Commonwealth countries are in the spotlight along the much discussed EU-UK relationship. Much of the attention has been given to the UK-US "Open Skies" agreement due to the North Atlantic traffic as both countries take the biggest share of the sector.

In the latter part of 2019, the aviation sector was exposed to cases of industrial action in British Airways and Ryanair. Linked to terms and conditions for their flight crews, namely pay increases in the case of British Airways and contractual improvements for Ryanair pilots, both these industrial actions demonstrated that despite the market challenges and Brexit uncertainty, the industry was in a prosperous state.

Airlines open to recruitment demonstrated that there was a staff shortage. Prospering businesses had the ability to absorb employees from businesses that were vulnerable to the strongly competing environment. In September 2019, the first and oldest tour operator in the world, Britains Thomas Cook, went into administration. This was caused by a combination of factors, such as changes of the business and leisure markets, competition from online travel agents and low-cost airlines, political unrest in other areas of the world and a lack of 
management control. Furthermore, the largest potential investor from China was prevented from purchasing a majority of shares due to the EU-ownership rules. In early March 2020 saw Flybe fall into administration. Flybe was a British regional operator that despite its takeover by a consortium of Virgin Atlantic, Stobart Group and Cyrus Capital; plus requests to the Government to discount the APD (Airport Passenger Duty) for its domestic flights, was not able to secure enough financial aid to keep operating. Apart from the APD issue, the airline was particularly vulnerable to domestic market demand as $40 \%$ of its flights were regional flights across the UK where the market was incredibly competitive [19].

Since March 2020, the current state of play has been largely affected by the recent COVID-19 crisis. Border and travel restrictions and the ever-changing self-isolation rules for arriving passengers are causing major disruption to the operators. Some airlines have been approved state financial aid while most of the airline and airport staff have been kept on furlough with the Job Retention Scheme (JRS). However, a series of S188 letters on collective redundancies have been issued by several operators, such as British Airways, BA Cityflyer, Virgin Atlantic, easyJet and Jet2. The majority of the potential collective redundancies were reduced by voluntary measures and by operators being able to offer voluntary redundancy packages, early retirements, leave of absence, various part-time options or a talent pool. More collective redundancies can be expected once the scheme comes to its end on October 31 st, as the latest announced extension of the JRS, (over the six months winter period), does not reflect the need of the travel and Aviation industry for staff retention.

The effects of the COVID-19 crisis on UK aviation started to become apparent at an early stage. The UK, having the world's third largest aviation sector, connects with its global partners where air travel can be crucial to ongoing businesses. Therefore, the Government has not given a mandate to stop any flights. The current reduction in traffic is primarily affected by border closures, states travel restrictions, updates in the quarantine exemption list but also shows a reduced demand in flying where operating a flight is not a viable option with some operators. As per the latest available update from EUROCONTROL [20] based on traffic level figures, the UK is the second busiest after Germany with 2,373 flights, with a $3 \%$ decrease in the past two weeks. In comparison with the previous year, air traffic in the United Kingdom is $63 \%$ lower regarding the amount of departure/arrival flights. However domestically, there has been an increase of $13 \%$ in flights taking place in the past two weeks.

The macroeconomic curve change proves again that the aviation sector, similarly to any other crisis, is amongst the first to be affected and will require much longer than other industries to deal with the crisis consequences. Data updates provided by EUROCONTROL on a regular basis demonstrate that the industry is averaging $50 \%$ below the previous years' levels, and there is no positive outlook for an improvement for the upcoming winter schedule [21].

\subsection{Future scope}

Whilst various EU trade models, such as the Norwegian or Swiss models were considered initially, it appears that the EU-UK model will be unique and the scope will reflect the need for flexibility but consistency. It is now clear that after the transition period ceases on the 31 st December 2020, non-EU agreements will take place. The negotiations are still ongoing as some issues remain unresolved, and there is a high possibility that the deal might be arranged very close to the deadline, if not even towards the very end of the transition period. However, Brexit negotiations have never stopped and have been progressing along with other major global and regional issues.

A future agreement on EU-UK relationship and the UK's participation in EU programmes will be a bilateral agreement, meaning that the EU will sign collective agreements with the 
UK rather than individual states separately. The ongoing negotiations are treated in "parallelism", where all partial negotiations in different sectors will be closed up when outstanding issues in all areas, such as fishing or the Irish border, are agreed upon.

According to statement from the EU's Chief Brexit Negotiator, Michel Barnier early in July [22], the EU's position remains, based on the Political Declaration, that there will be no economic partnership without:

- robust guarantees for a level playing field - including on state aid - to ensure open and fair competition among our businesses;

- a balanced, sustainable and long-term solution for our European fishermen and women;

- an overarching institutional framework and effective dispute settlement mechanisms.

Mr. Barnier further confirms that the EU negotiators will continue to insist on parallel progress on all areas.

\section{Discussion}

Separate agreements that are expected to be signed with individual states are those concerning air service agreements (ASA) as all EU carriers will become foreign carriers and will require a Third Country Operators Certificate (TCO). Every operator will therefore need such an approval in order to be able to operate flights to and from the UK. Issues such as ownership, right to operate, cabotage or licence validity have been questioned by businesses in the industry.

Regarding freedoms of the air, changes will apply as the UK will most likely no longer have access to the single market. Third and forth freedoms will still apply, however, cabotage will not be available. Airline operators have been requesting Aircraft Operator Certificates (AOC) with local regulators in order to enable the continuity of their services after the $31 \mathrm{st}$ December, e.g., easyJet gained their Austrian AOC whilst Ryanair and Wizzair have established AOCs in the UK. EU-ownership rights will remain in question as these might be required for those who have established an EU-AOC to guarantee their services. For cargo operators who operate on British registered aircraft across airfields in Europe, the loss of market access and cabotage privileges will pose many complications.

Since it has been confirmed that the UK will also leave EASA, the process of license and approval conversions is in place to ensure continuity once the actual EASA withdrawal happens. It appears that leaving EASA, an agency that the UK has invested a lot of expertise in, has been the most suitable option to reflect UK's need for flexibility in the new "Global Britain". As with most EU institutions, only EU member states have voting rights, meaning that the UK as the largest aviation sector in Europe would loose such a privilege and therefore, its ability to shape the future regulation-making process would be reduced. It is also questionable how much leeway on such processes the UK will have outside EASA, and whether there will be a greater allowance for diversions from the existing and future rules. In the near future, it is expected that there will be very little difference from EASA regulations - the most relevant rules will be brought in from EU law and those that do not apply will not be considered. Transferring the existing law is certainly more convenient than creating new rules. However, some adjustments will be required. The expected areas of disagreement could be around the ownership rights or secondary legislation (Statutory Instruments). Overall, there would be an aim for flexibility, efficiency and professionalism.

Regarding the transition, EASA is currently processing conversions within the early applications process that concern: [23]

- Aero-Medical Centre (AeMC) Certificates

- ATM/ANS

- Approved Training Organisation (ATO) Approvals

- Continuing Airworthiness Management Organisation (CAMO) Approvals 
- Flight Simulator Training Device (FSTD) Qualification certificates

- Maintenance Organisation Approvals (MOA)

- Maintenance Training Organisation Approvals (MTOA)

- Production Organisations Approval (POA)

- Third Country Operators (TCO) Authorisation

When it comes to the licensing sector, all UK licenses will revert to an ICAO status from the 1st January 2021. There will be no reciprocity from the EASA side, therefore, UK license holders who wish to keep their EASA license status, were recommended to convert their licenses to another EASA State. These conversions, as discussed above, involve various sectors, such as flight crew licenses, maintenance and training organization approvals or simulator training devices. The UK CAA will continue to recognize EASA licenses and approvals for a period of two years; to allow for a national license or approval conversion. The UK CAA has been profound in giving a maximum flexibility to the operators, however, companies that wish to operate their services on both sides of the channel will need to obtain parallel approvals. Whether the UK and the reciprocal regulator will grant any future interoperability, remains in question.

The operational characteristics of the specific market are often defined by geography and may limit new competitors to enter the market; which is relevant to the transatlantic market. Regulatory limitations, which include airline ownership, charging and capacity allocation rules, may also limit the options [9]. The favourable geographical position of the British Isles in the North Atlantic will not change by any political circumstances. Therefore, the authors predict that there will be little impact of Brexit on transatlantic travel. However, regulatory limitations might remain a challenge with respect to connecting to the EU and US via the UK, should a no deal scenario occur.

Brexit will undoubtedly give the UK more flexibility in forming trade deals with third countries and focus on issues that are more relevant to trade partners. There are positive signs that negotiations with third countries, such as the US have been finalised; in contrast to the ongoing EU-UK talks about future relationships.

To note, the new "open skies" air services arrangement with the US was signed in November 2018, meaning that there will be continuity of service with regards to the transatlantic travel. The UK Government has also confirmed further bilateral agreements with Albania, Georgia, Iceland, Israel, Kosovo, Montenegro, Morocco and Switzerland [24]. Negotiations on trade deals with other important partners, such as Australia or New Zealand are ongoing.

\section{Conclusions}

Whilst negotiations on the future trade and bilateral agreements are in progress and no official EU-UK agreement has been presented to this date, there are a few items that can be predicted with a certain level of confidence. If no extension to the transition period will take place, the UK will loose all EU membership rights and open market access after the 31st December 2020 , providing no deal is agreed on. Should there be any trade agreements in place, certain rights and privileges can be maintained, depending on the scope of these agreements. The UK aviation industry will, with its non-EU membership status, revert to ICAO status. When the actual EASA withdrawal takes place, a non-EASA compliance mandate should grant the UK more freedom in shaping the future of its aviation sector. However, it is difficult to predict how far UK regulations will diverge from EASA's. The shift is expected to be rather slow or subtle and will depend on the level of future cooperation.

The withdrawal from EASA also poses questions about the future EU-UK relationships and the extent of cooperation in important areas such as GALILEO GNSS, development and aircraft manufacturing. Not all freedoms of the air are expected be available; especially when 
it comes to cabotage or interoperability. Some operators, such easyJet, Norwegian, Ryanair or Wizzair have been preparing for the continuity of their services by establishing another AOC or recommending their crew members to other-than-UK EASA licence conversion. However, the heavy burden of the ongoing pandemic makes it difficult to establish the true impact of Brexit on the industry's performance or the job market.

Should there be a deal or a no deal, there is a broad recognition that Brexit will have a significant effect on aviation, an industry that is highly dependent on globalised and liberal market access due to its international nature.

\section{References}

1. Airport Council International (2019). World's 20 busiest airports (Total Passenger Traffic). Airport Council International. Retrieved from : https://aci.aero/wpcontent/uploads/2019/03/2486_Top-20-Busiest-Airport_passenger_v3_web.pdf

2. Sustainable Aviation (2016). UK Aviation Industry Socio-Economic Report. Airlines UK. Retrieved from : https://airlinesuk.org/wp-content/uploads/2016/02/SA-SocioEconomic-Report-Final.pdf

3. Pitfield, D. E. (2009). The assessment of the EU-US Open Skies Agreement: The counterfactual and other difficulties. Journal of Air Transport Management, 15, 308314.

4. Walulik, J. (2020, April 14). Assessing the UK's plans for an independent aviation safety regulator. LSE European Politics and Policy (EUROPP) Blog. Retrieved from : http://eprints.1se.ac.uk/105205/1/europpblog_2020_04_14_assessing_the_uks_plans_fo $r \_$an_independent.pdf

5. Fox, S. J. (2016). BREXIT: A Bolt from the Blue! - Red Sky in the Morning? Issues in Aviation Law and Policy, 16(1), 83-120.

6. Hill, P., Korczak, A., Korczak, P. (2019). Political Uncertainty of Individual Companies: The Case of the Brexit Referendum. Journal of Banking and Finance, 100, 58-76.

7. Campante, F., Yanagizawa-Drott, D. (2017) Long-Range Growth: Economic Development in the Global Network of Air Links. The Quarterly Journal of Economics, 133(3), 1395-1458.

8. Glencross, A., McCourt, D. (2018). Living Up to a New Role in the World: The Challenges of "Global Britain". Orbis, 62(4), 582-597.

9. Christidis, P. (2016). Four shades of Open Skies: European Union and four main external partners. Journal of Transport Geography, 50, 105-114.

10. Oum, T. H., Zhang, A., Fu, X. (2010). Air transport liberalization and its impacts on airline competition and air passenger traffic. Transport Journal, 49, 24-41.

11. Goetz, A. R., Vowles, T. M. (2009). The good, the bad and the ugly: 30 years of US airline deregulation. Journal of Transport Geography, 17(4), 251-263.

12. Dobruszkes, F. (2019). Air services at risk: The threat of a hard Brexit at the airport level. Economy and Space, 51(1), 3-7.

13. Kupelian, B. (2020, January). Predictions for 2020: "Slowbalisation" is the new globalisation. Plobal. Retrieved from : https://www.pwc.com/gx/en/issues/economy/global-economywatch/assets/pdfs/predictions-2020.pdf 
14. Brezonakova, A., Badanik, B., (2017). Looking Beyond the Brexit in Aviation. In T. Kliestik (Ed.), Procedings of the 17th International Scientific Conference Globalization and Its Socio-Economic Consequences (pp. 210-217). Zilina: University of Zilina

15. Brezonakova, A., Badánik, B., Davies, R. (2020). Brexit in Aviation: 2019 Update. In Proceedings of 23rd International Scientific Conference Transport Means 2019 (pp. 253-261). Palanga.

16. Walulik, J. (2019). Brexit and Aviation Law. Book Series: Legal Perspectives on Brexit. Oxford: Routledge.

17. Vrbaski, L. (2016). Flying into the Unknown: The UK's Air Transport Relations with the European Union and Third Countries Following 'Brexit'. Air \& Space Law, 41(6), 421-444.

18. Pappas, N. (2019) UK outbound travel and Brexit complexity. Tourism Management, $72,12-22$.

19. Lawrie, E. (2020, March 5). Flybe collapse: Five things that went wrong. BBC News. Retrieved from : https://www.bbc.com/news/business-51749882

20. Eurocontrol (2020, September 23). COVID19 Impact on European Air Traffic Eurocontrol Comprehensive Assessment, Wednesday, 23 September 2020. Eurocontrol. Retrieved from : https://www.eurocontrol.int/sites/default/files/2020-09/covid19eurocontrol-comprehensive-air-traffic-assessment-23092020.pdf

21. Eurocontrol (2020, September 23). EUROCONTROL Comprehensive Assessment of COVID-19's Impact on European Air Traffic. Eurocontrol. Retrieved from : https://www.eurocontrol.int/publication/eurocontrol-comprehensive-assessment-covid19s-impact-european-air-traffic

22. Ferrie, D. (2020, July 2). Statement by Michel Barnier following the restricted round of negotiations for a new partnership between the European Union and the United Kingdom. European Commission Press Corner. Retrieved from : https://ec.europa.eu/commission/presscorner/detail/en/SPEECH_20_1262

23. EASA (2020). Early applications related to Brexit. EASA. Retrieved from : https://www.easa.europa.eu/brexit-early-applications

24. Department for Transport (2018, November 28). US and UK agree on new open skies arrangements. Gov.uk. Retrieved from : https://www.gov.uk/government/news/uk-andus-agree-new-open-skies-arrangements 